O corpo editorial do boletim da SPQ tem vindo a fazer um enorme esforço para produzir uma revista que possa reflectir a actividade da química em Portugal e alargar a participação dos químicos portugueses. Mas este é um objectivo difícil e não isento de contradições. Porque por um lado apelamos à participação e por outro seleccionamos os artigos de acordo com critérios de qualidade e de oportunidade. Por outras palavras, nem todos os bons artigos científicos podem ser publicados neste boletim. Trabalhos muito especializados não se enquadram numa publicação que pretende chegar a um público diversificado. Neste enquadramento, por vezes rejeitamos artigos. 0 que é um aparente contra-senso para quem quer alargar a participação. Mas trata-se da regra do jogo e quem quer ver os seus trabalhos publicados a ela tem de se submeter.

Não sabemos, por falta de estatísticas, qual o verdadeiro índice de leitura do nosso boletim. $\mathrm{O}$ que podemos dizer é que a nossa tentativa de promover uma rubrica de cartas ao editor não tem tido sucesso. Pode ser por falta de hábito de polémica, ou por outra razão qualquer. Mas sentimos isso como uma ausência de dinamismo nossa e também dos nossos leitores. Como dizem os treinadores de futebol, esse grande paradigma da nossa sociedade actual, e a mãe de todos os interesses, vamos continuar a trabalhar.

Motivos de leitura neste número não fal- tam; desde as rubricas habituais, artigos científicos, à entrevista com o Prof. Sebastião Formosinho para a qual nos permitimos chamar a atenção dos nossos leitores.

O Outono chegou, caminhamos para o Inverno, que dará lugar à Primavera e de novo ao Verão. 4 estações - 4 números do boletim. É uma banalidade, mas a vida na ciência é feita destas rotinas, do trabalho continuado, tantas vezes um pouco repetitivo. As mudanças são lentas e dão trabalho. Por isso caro leitor. aceite o desafio e envie artigos de qualidade e de interesse geral. Mande cartas ao editor. Ajude a criar neste boletim um espaço de reflexão, de discussão e porque não, de confronto de ideias e de projectos.

\title{
NATIRIŔRI SPR
}

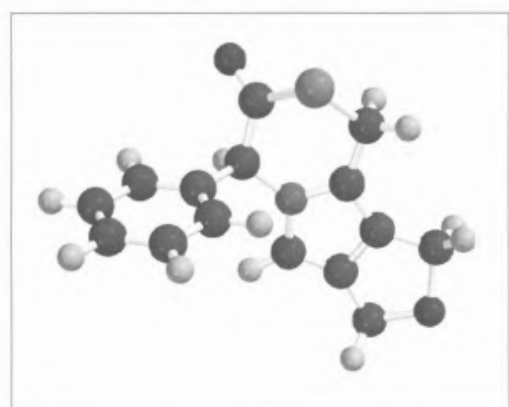

\section{Simpósio de Química de Compostos Heterocíclicos}

Divisão de Química Orgânica da Sociedade Portuguesa de Química Departamento de Química da Universidade do Minho

\section{5 de Novembro de 2002}

A Divisão de Química Orgânica da Sociedade Portuguesa de Química tomou a iniciativa de organizar Simpósios Temáticos de dois em dois anos alternan- do com os Encontros Nacionais de Química Orgânica. A série iniciou-se com o Simpósio de Espectroscopia de Ressonância Magnética Nuclear que teve lugar na Universidade de Aveiro em Outubro de 2000. No corrente ano irá realizar-se o Simpósio de Química de Compostos Heterocíclicos, no dia 25 de Novembro, na Universidade do Minho. A selecção deste tema tem justificação se pensarmos que quase metade dos compostos orgânicos conhecidos incluem na sua estrutura pelo menos um anel heterocíclico. São uma classe de compostos com um conjunto vastíssimo de aplicações nomeadamente na Medicina e na Indústria. Existem igualmente muitos compostos heterocíclicos que são compostos naturais com importan- tes funções em processos biológicos. A sintese e reactividade de compostos heterocíclicos é actualmente objecto de estudo de vários grupos de investigação no país pelo que o Simpósio de Química de Compostos Heterocíclicos será um local privilegiado para que estudantes de pós-graduação e investigadores debatam temas de interesse comum. 0 Simpósio contará com a contribuição de oradores nacionais e estrangeiros pretendendo abranger um leque alargado de tópicos da área da Química de Compostos Heterocíclicos.

Contacto amcampos@quimica.uminho.pt 


\section{Olimpíadas de Química 2002}

Com a realização da Final a 4 de Maio (na Universidade de Aveiro), terminou a edição de 2002 das Olimpíadas Portuguesas de Química.

Tal como nos anos anteriores, a prova foi realizada em três fases. A $1 .^{\circ}$ fase decorreu nas escolas, com a selecção de uma equipa de 3 alunos do $11 .^{\circ}$ e $12 .^{\circ}$ anos. Participaram 465 alunos de 66 escolas secundárias. Seguiram-se as semifinais ( $2^{\mathrm{a}}$ fase), realizadas com a já habitual colaboração das Universidades de Lisboa (IST), Porto (DQ) e Aveiro (DQ). Os 27 alunos apurados (correspondentes a nove equipas), defrontaram-se individualmente na Final, para apuramento dos vencedores absolutos de 2002 e selecção da equipa de representantes portugueses nas competições internacionais (neste caso, Olimpíadas Iberoamericanas, Mar del Plata, Argentina).

A edição deste ano consolidou as características que estão a tornar as Olimpíadas de Química uma realização bem conseguida da SPQ, mas também marca o início de uma nova etapa de amadurecimento. A selecção da $1^{\text {a }}$ fase, realizada nas escolas, continua a ser uma excelente oportunidade para dinamizar o estudo da química. Os testes das semifinais dos anos anteriores estão disponiveis na página da SPQ e podem constituir uma base de preparação prévia para a competição. As semifinais continuam a ser um bom pretexto para ficar a conhecer melhor as universidades (onde alguns participantes estudarão no ano seguinte...). Na final, foi possivel introduzir pela primeira vez a realização de uma prova prática indivi-

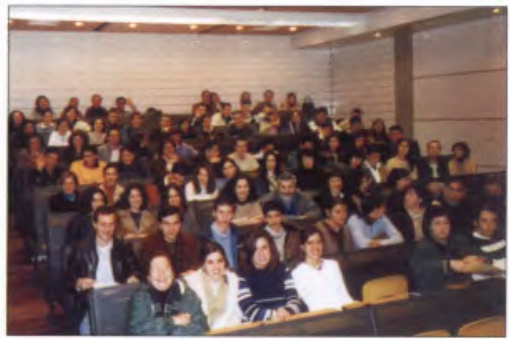

figura 1 Semifinal de Lisboa: a boa disposição participantes. dual (Ciclo do Cobre - ver caixa), uma opção que se pretende manter tanto quanto possivel. E agora começa a surgir o desafio das competições internacionais: a SPQ já assegurou a participação de equipas portuguesas nas Olimpíadas Ibero-americanas, nas Olimpíadas Internacionais, e foi convidada a participar nas Olimpíadas Europeias de Ciência... 2003 pode ser um ano bastante "frenético" para os estudantes e mentores!

\section{Classificação Final}

Medalha de ouro

Ana Raquel Sequeira Pinto, ES Alves Martins (Viseu)

Medalha de Prata

Angela Filipa Pereira Cardoso,Externato Delfim Ferreira (Riba d'Ave)

Medalha de Bronze

Humberto Bento Ayres Pereira, Colégio Cedros (Vila Nova de Gaia)

4. ${ }^{\circ}$ Classificado (apurado para as Iberoamericanas)

Carlos Jorge da Silva Andrade, ES/B3 de Estarreja

\section{Semifinal de Aveiro}

\section{Medalhas de Ouro}

Carlos Jorge da Silva Andrade, José CarIos Silva Russo, Miguel Vidal Drummond (ES/B3 de Estarreja)

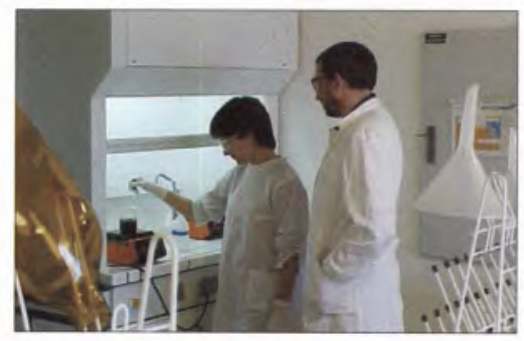

figura 2 Prova laboratorial: um momento do "Ciclo do Cobre"
Medalhas de Prata

Ana Filipa Bernardino Simões, João Rui Nunes e Silva, Inês Isabel Vasconcelos (ES de José Falcão)

\section{Medalhas de Bronze}

Daniela Patrícia Leitão Silva, Ana Raquel Sequeira Pinto, Inês Isabel Ribeiro CoeIho(ES Alves Martins )

\section{Semifinal de Lisboa}

Medalhas de Ouro

Manuel Nascimento, Sílvia Marques, Filipe Ataíde (ES/B3 Padre António Macedo)

\section{Medalhas de Prata}

Catarina Catroga, Ana Luísa Afonso, Daniela Santos (Instituto de Odivelas)

\section{Medalhas de Bronze}

Luísa Maria Martins Pires, Ana Filipa Martins Pires, Mariana Monteiro Inácio (ES/B3 de Peniche)

\section{Semifinal do Porto}

\section{Medalhas de Ouro}

Humberto Bento Ayres Pereira, Rafael Guedes Souza, Tiago Luís Sousa Veloso (Colégio Cedros )

\section{Medalhas de Prata}

ngela Filipa Pereira Cardoso, Pedro Miguel Rodrigues, Renato Gondar (Externato Delfim Ferreira )

Medalhas de Bronze

Afonso Ferreira Neves, Daniel da Costa Pinto, Ana Filomena Oliveira (Colégio Internato dos Carvalhos) Olimpíadas de Química 2002.

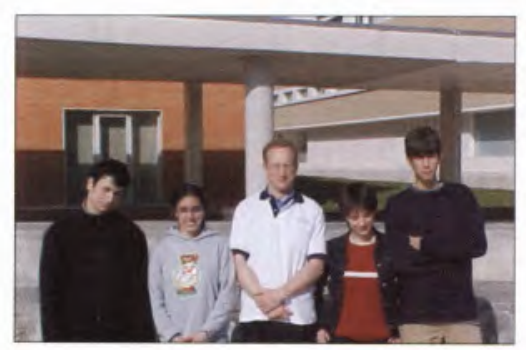

figura 30 coordenador das Olimpiadas e os vencedores de 2002 (da esquerda para a direita, Carlos Jorge, Ana Raquel, Angela Filipa e Humberto Bento). 


\section{Prelúdio da prova laboratorial}

O prova prática da Final das Olimpíadas, com o título "Ciclo do Cobre" e baseada num trabalho prático da disciplina de Química II (Prof. J. J. C. Teixeira Dias), envolveu um conjunto de reacções de transformação do cobre, que começa e acaba com cobre metálico. 0 trabalho é bastante apelativo para os alunos (vapores rutilantes, variações de cor, precipitação), mas a sua realização exige muita atenção às questões de segurança em laboratório. Por esse motivo, além dos habituais avisos - que os alunos nem sempre lêem/ouvem algumas horas antes foi-Ihes distribuído o texto abaixo, que por levantar um pouco o véu sobre o conteúdo da prova prática foi avidamente lido:

Durante a leitura de um livro de texto de química, encontrei a afirmação "o ácido nitrico actua sobre o cobre". Eu estava a ficar farto de ler este tipo de frase absurda e determinado a descobrir o que é que queria dizer. $O$ cobre era-me mais ou menos familiar, pois usavam-se ainda cêntimos de cobre. E eu tinha visto uma garrafa com o rótulo "Ácido nítrico" [...]. Eu não conhecia as suas particularidades, mas estava entusiasmado e desejoso de aprender. 0 espírito da aventura tinha-me dominado. Tendo ácido nítrico e cobre, eu tinha apenas que descobrir o significado da expressão "actua sobre". Assim, a afirmação "o ácido nítrico actua sobre o cobre" passaria a fazer algum sentido.

Tinha tudo preparado. No interesse da ciência, estava até disposto a sacrificar um dos poucos cêntimos de cobre que possuía. Pus um deles sobre a mesa; abri a garrafa rotulada "Ácido nítrico"; verti algum do líquido sobre o cobre e preparei-me para fazer a observação.

Mas que maravilha era aquela ante os meus olhos? O cêntimo já tinha mudado, e não pouco. Um líquido verde-azulado espumava e fumegava sobre a moeda e a mesa. $\mathrm{O}$ ar à volta tornou-se vermelho escuro. Uma grande nuvem colorida apareceu. $E$ era desagradável e sufocante - como é que eu podia parar aquilo? Tentei ver-me livre daquela trapalhada pegando na moeda e atirando-a pela janela, que entretanto abrira. E aprendi outro facto: o ácido nítrico actua sobre o cobre e também actua sobre os dedos. A dor levou-me a outra experiência não planeada. Esfreguei os dedos nas calças e descobri mais um facto. $O$ ácido nítrico também actua sobre as calças.

Tomando tudo em consideração, foi uma experiência impressionante $e$, em termos relativos, provavelmente a mais dispendiosa que alguma vez efectuei. Ainda hoje falo dela com interesse. Foi uma revelação para mim. Resultou do meu desejo de aprender mais acerca daquele tipo de acção. Obviamente, a única forma de aprender sobre ela é ver os seus resultados, experimentar, trabaIhar no laboratório.

Tradução livre de um texto de Ira Remsen (1846-1927), autor de um livro de texto de química publicado em 1901, e co-descobridor da sacarina.

Este texto é divertido e expressa um entusiasmo pela química que queremos cultivar. Ira Remsen também reconheceu a importância vital das experiências laboratoriais em química. Contudo, ele teve muita sorte por não ter sofrido consequências mais graves nesta experiência. A actividade experimental nunca deve ser conduzida com os métodos aqui descritos. Para pensar: quais as Regras de Segurança de Laboratório claramente desrespeitadas na "experiência" descrita por Remsen?

Hoje existe uma certa tendência a privilegiar a investigação aplicada em relação à fundamental. Mas a história da ciência ensina-nos que é a investigação científica fundamental aquela que mais contribui para o progresso da humanidade. Poder-se-ia dar tantos exemplos. Limito-me a mencionar uma anedota em que se conta que, no século passado, quando o Primeiro Ministro inglês Gladstone foi visitar o laboratório do famoso cientista Faraday, perguntou se aquela substância esotérica, chamada electricidade, sobre a qual Faraday estava fazendo experiências, teria alguma vez uma qualquer aplicação prática. A resposta de Faraday foi lapidar: "Esta substância que Vossa Excelência chama esotérica, senhor Ministro, um dia pagará imposto." 